\title{
Secreted and Membrane-Bound Mucins and Idiopathic Peptic Ulcer Disease
}

\author{
Yaron Niv Doron Boltin \\ Department of Gastroenterology, Rabin Medical Center, Tel Aviv University, Tel Aviv, Israel
}

\section{Key Words}

Peptic ulcer · Mucin · Aspirin · Helicobacter pylori

\begin{abstract}
The incidence of Helicobacter pylori and non-steroidal antiinflammatory drug (NSAID)-negative peptic ulcer disease has increased over the last two decades, especially in the Western world and in countries with low $\mathrm{H}$. pylori infection rates. Idiopathic peptic ulcer disease is a recently described entity which relates to peptic ulcers not caused by $H$. pylori, NSAID/aspirin therapy, other ulcerogenic organisms and drugs, or other rare malignant and benign diseases. Structural and secreted mucins create the unstirred gastric mucus layer and maintain a stable $\mathrm{pH}$ above the gastric mucosa. This mucous layer prevents enzymatic attack by acid and pepsin. Inhibition of cyclooxygenase by NSAID and aspirin inhibits prostaglandin production, inhibits mucin and bicarbonate secretion, and exposes the mucosa to the toxic effects of acid and intragastric enzymes. There is also a complex relationship between $H$. pylori and different mucin subtypes which on one hand facilitates mucin invasion but on the other hand protects the gastric mucosa. Genetic and epigenetic changes in the mucin molecule may be responsible for idiopathic peptic ulcer disease, but this hypothesis must be further investigated. Herein, the mucin hypothesis of idiopathic peptic ulcer disease is explored.
\end{abstract}

(C) 2012 S. Karger AG, Basel

$0012-2823 / 12 / 0863-0258 \$ 38.00 / 0$

Fax +41613061234

E-Mail karger@karger.ch

www.karger.com
Accessible online at: www.karger.com/dig

\section{Introduction}

The incidence of Helicobacter pylori and non-steroidal anti-inflammatory drug (NSAID) or aspirin-negative peptic ulcer disease has increased steadily over the last two decades, especially in the USA and Western Europe, and in countries where $H$. pylori infection rates are low or declining [1]. It has been proposed that the incidence of idiopathic peptic ulcer disease varies inversely with $H$. pylori infection rates in a given population [2]. This hypothesis has no rational basis and relies on mathematical evaluations. In actual fact, in some high $H$. $p y$ lori prevalence countries the rate of idiopathic peptic ulcer disease is high, and in some countries with a low prevalence of $H$. pylori infection the rate of idiopathic peptic ulcer disease is low (table 1). For example, in Pakistan and Japan, both high $H$. pylori prevalence countries, the prevalence of $H$. pylori-negative/NSAID-negative ulcers is 29 and $1.3 \%$, respectively, indicating that there is not inverse variance with $H$. pylori prevalence (table 1) [3-9]. In two cohorts from Hong Kong, the prevalence of $H$. pylori/NSAID-negative peptic ulcer ranged from $4.1 \%$ up to $17 \%[6,10]$.

The prevalence of idiopathic peptic ulcer disease is probably influenced by a balance between protective and noxious factors, which may differ from one cohort to another. Although the definition of idiopathic peptic ulcer disease requires the exclusion of noxious factors, such as 
H. pylori, NSAID/aspirin therapy and infectious disease, one must also take into account defensive mechanisms such as mucin and bicarbonate secretion.

\section{Idiopathic Peptic Ulcer Disease}

Twelve etiologies have been described for peptic ulcer disease, and should all be excluded before establishing a diagnosis of idiopathic peptic ulcer disease [1]. These include $H$. pylori infection, NSAID/aspirin therapy, other drugs, other infectious organisms (e.g. cytomegalovirus or herpes simplex infection, in particular in immunocompromised patients, or colonization of the stomach with Helicobacter heilmani), tumors, Crohn's disease of the stomach or duodenum, eosinophilic gastroduodenitis, irradiation therapy and rare malignant and benign diseases such as Zollinger-Ellison syndrome or systemic mastocytosis. Stress ulcers from trauma, burns, and multiorgan failure must also be excluded. The validity of the drug history should be ascertained. Over-the-counter drugs, herbal medications and surreptitious use of aspirin must be considered. Rebound acid secretion after withdrawal of a proton pump inhibitor (PPI) is another possibility.

Before diagnosing idiopathic peptic ulcer disease, one must be confident that $H$. pylori tests are truly negative. The sensitivity of ${ }^{13} \mathrm{C}$-urease breath tests, stool antigen tests, histology, urease tests and culture is over $90 \%$. The sensitivity of serology may be as low as $60 \%$ depending on the specific kit. In up to $10 \%$ of $H$. pylori-positive cases, the ulcer persists after successful eradication, indicating that causes other than $H$. pylori infection may be at play [2]. In such cases, $H$. pylori may be an innocent bystander. H. pylori duodenal colonization or infection with $H$. heilmani should be excluded.

\section{Mucin Structure and Classification}

Mucins are high molecular weight glycoproteins with a protein backbone and oligosaccharide side chains attached to serine or threonine residues via O-glycosidic linkages. Mucins are produced by various specialized epithelial cells, especially goblet cells. They play an important protective role by forming a physical, chemical and immunological barrier between the lumen and the epithelial surface. Mucins can be divided into two categories - secreted and membrane-associated (structural) [11]. Secreted mucins can be further subdivided into
Table 1. Epidemiology of $H$. pylori/NSAID-negative peptic ulcer

\begin{tabular}{lll}
\hline $\begin{array}{l}\text { Prevalence } \\
\%\end{array}$ & Country & Source \\
\hline 39 & USA & Jyotheeswaran et al., 1998 [3] \\
29 & Pakistan & Yakoob et al., 2005 [4] \\
27 & USA & Ciociola et al., 1999 [5] \\
4.1 & Hong Kong & Chan et al., 2001 (bleeding) [6] \\
$1.6(\mathrm{DU}), 4.1(\mathrm{GU})$ & Spain & Arroyo et al., 2004 [7] \\
1.3 & Japan & Nishikawa et al., 2000 [8] \\
0.8 & Spain & Gisbert et al., 1999 [9] \\
17 & Hong Kong & Xia et al., 2001 [10] \\
\hline
\end{tabular}

$\mathrm{DU}=$ Duodenal ulcer; $\mathrm{GU}$ = gastric ulcer.

gel-forming mucins (MUC2, MUC5AC, MUC5B, MUC6, MUC19) and non-gel-forming mucins (MUC7, MUC8). There are 11 membrane-associated mucins (MUC1, MUC3A, MUC3B, MUC4, MUC12, MUC13, MUC15, MUC16, MUC17, MUC20 and MUC21). All mucins have at least one mucin-like domain formed by a variable number of tandem repeats (VNTR) rich in proline, serine and threonine residues. These domains carry the typical mucin $\mathrm{O}$-glycosylations. The secreted gel-forming mucins undergo oligomerization through the formation of disulfide bridges between cysteine residues. Secreted non-gel-forming mucins are not able to oligomerize, and their structural and functional properties are poorly described [12]. Membrane-associated mucins do not oligomerize and are present on the apical membrane of epithelial cells where they are involved in cell signaling. Some membrane-associated mucins can be found in the mucus layer, together with the secreted mucins, probably as a consequence of proteolytic cleavage or due to the expression of secreted splicing variants [13].

\section{Mucin Role in Protection against Ulcer Formation}

If a peptic ulcer is not related to $H$. pylori infection, NSAID or aspirin therapy or any of the aforementioned causes, what is the etiopathogenesis of this disease? The most accepted theory of ulcer formation in the upper gastrointestinal tract centers on the disruption of a delicate equilibrium between the destructive effects of acid, pepsin and other toxic substances, and the protective effects of growth factors, bicarbonate and mucin. Mucin is an ideal candidate for investigation in this regard. 
Mucin is the primary agent which lends protection against acid and pepsin. Thus, any derangement in mucin secretion, quantitative or qualitative, may be deleterious. Secretion of mucin is mediated by prostaglandin $E_{2}$ $\left(\mathrm{PGE}_{2}\right)$ and supported by nitric oxide, hydrogen sulfide, growth factors and trefoil peptides [14]. The mucin-unstirred layer maintains a stable $\mathrm{pH}$ above the mucosa and prevents enzymatic attack by pepsin. Inhibition of cyclooxygenase by NSAID and aspirin prevents mucin secretion and exposes the mucosa to the toxic effects of acid and enzymes. Therefore, not only NSAIDs, but any agent which interferes with mucin secretion can cause peptic ulcer disease.

Mucin gene expression is organ-specific and tissues can be characterized by identifying their mucin proteins or specific RNA. Since different glycosyltransferases are involved in the glycosylation of the protein backbone and elongation of sugar side chains, there is a huge scope for diversity and accurate mapping of mucins is difficult. Three main mucins have been described in the stomach: MUC1, a structural and almost universal mucin, and two secreted mucins, namely, MUC5AC and MUC6. Using immunohistochemistry with antibodies targeting the main secreted gastric mucins, MUC5AC and MUC6, we have previously demonstrated the laminated structure of these two species within the mucin-unstirred layer [15, 16]. MUC5AC is secreted by the superficial mucosal layer and is the main component of the mucus-unstirred layer. MUC6 is secreted by the deep mucosal glands, migrates to the lumen through the gland's orifice, and intersperses with MUC5AC. We have also demonstrated a gradient of MUC5AC expression from the surface to the glands, in both $H$. pylori-positive and negative patients, and a Ushape gradient of MUC6 expression, with highest expression in the deep glands. Furthermore, we demonstrated by dual staining that the adherent gastric mucous layer is composed of alternating layers of MUC5AC and MUC6 mucin proteins [17]. This particular structure may be important for $H$. pylori colonization.

\section{Relationship between H. pylori and Gastric Mucin}

Mucin, NSAID and H. pylori have a 'love-hate relationship'. H. pylori decreases the mucin synthesis probably by inhibiting galactosyltransferase, the primary enzyme responsible for adding sugar residues to the protein backbone $[18,19]$.

This mechanism facilitates the passage of bacteria to the epithelium. Interestingly, mucin 'fights back'. Natu- ral antibiotic function of MUC6 against $H$. pylori has been demonstrated [20]. MUC6 O-glycans with terminal $\alpha_{1,4}$-linked $\mathrm{N}$-acetylglucosamine inhibit cholesteryl- $\alpha$ D-glucopyranoside within the bacterial wall, and inhibit $H$. pylori proliferation in a dose-dependent manner, thereby decreasing the bacterial burden. Other $H$. pylori virulence factors include a high concentration of urease available for secretion to the gastric lumen, and flagella which enable free swimming in a fluid milieu. The higher $\mathrm{pH}$ induced by $H$. pylori urease transforms mucin from a gel to solution and enhances $H$. pylori motility [21]. Bab A and Sab A adhesins on H. pylori bind to Lewis $\mathrm{b}$ and sialyl Lewis $\mathrm{X}$ blood group antigens on MUC5AC, facilitating colonization [22]. In addition, $\alpha_{1,4}$-linked $\mathrm{N}$-acetylglucosamine on MUC6 causes de novo expression of 6-sulfo-sialyl Lewis X on high endothelial venule-like vessels that together with the mimicry of Lewis blood groups between mucin and the bacterium lipopolysaccharide (LPS) prevent lymphocytic attack [22].

The membrane-bound mucin MUC1, detectable in normal gastric epithelium, similarly plays a role in gastric cytoprotection. In response to $H$. pylori infection, MUC1 is shed from the cell surface, thereby acting as a decoy to limit bacterial adhesion [23]. This process of shedding occurs when SabA and BabA bacterial antigens bind the mucin molecule. In the absence of these adhesins, MUC1 remains anchored to the gastric epithelium but still effectively blocks $H$. pylori adhesion by steric hindrance.

MUC5AC and MUC6 genes are located on the short arm of chromosome 11 [24]. It is speculated that genetic or epigenetic changes in these genes may influence mucin expression and decrease the protective capacity of the unstirred layer. There is some evidence that mucin expression is regulated by growth factors, interleukins and bacterial LPS [25-27]. Epidermal growth factor and interleukin-1 $\beta$ upregulate mucin expression, and LPS of Pseudomonas aeruginosa and Haemophilus influenzae upregulates MUC5AC and inhibits mucin glycosylation and sulfation. Thus, changes in mucin secretion and structure, initiated by the interaction between environmental factors such as drugs (aside from NSAID) and bacteria (aside from $H$. pylori) as well as host genetic factors, may be involved in non- $H$. pylori/non-NSAID peptic ulcer disease. Exploration of the exact underlying pathomechanisms is important since idiopathic peptic ulcer tends to be a severe disease. 
Table 2. Studies reporting demographic and clinical associations of $H$. pylori/NSAID-negative peptic ulcers

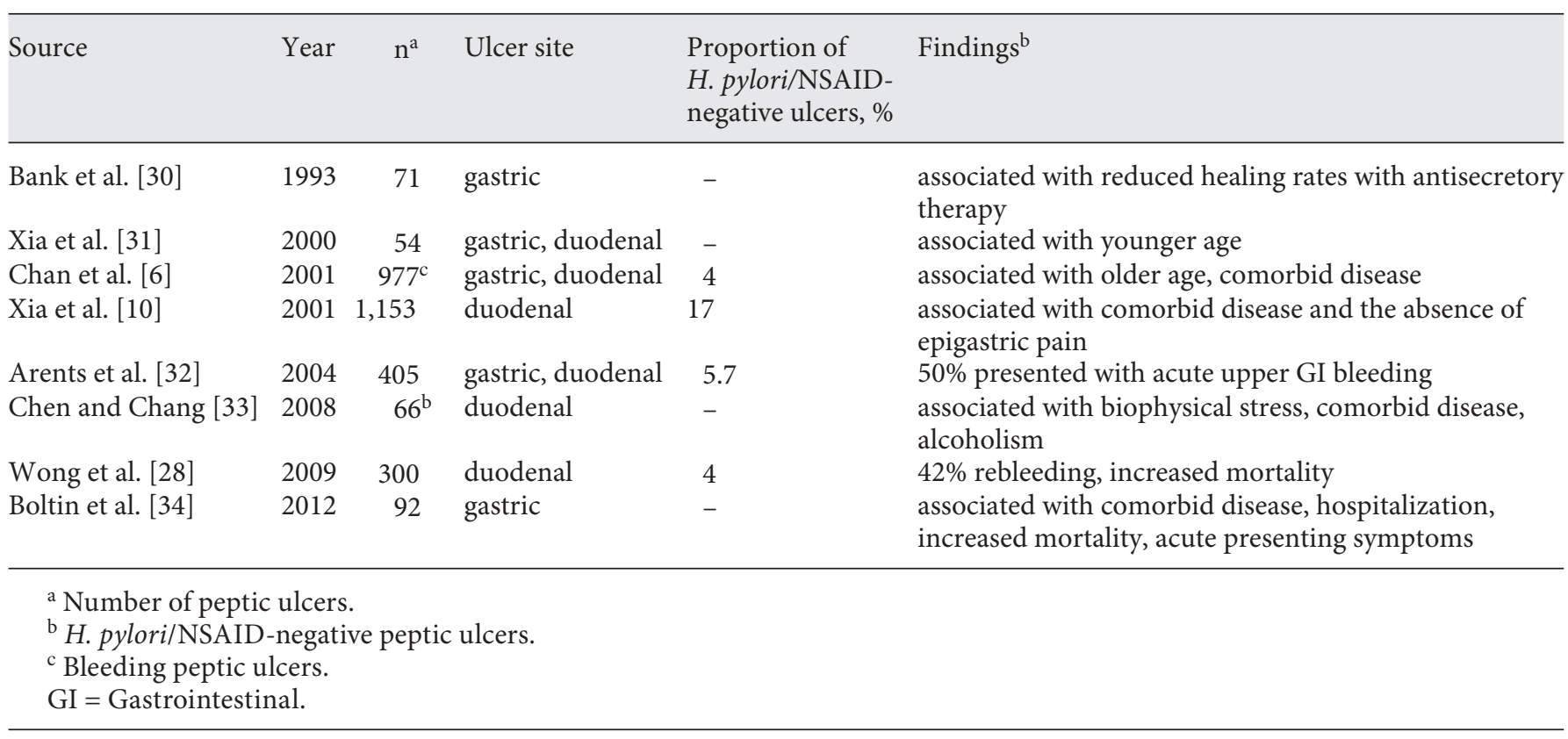

\section{Clinical Spectrum of Idiopathic Peptic Ulcer Disease}

There are accumulating data describing the aggressive nature of idiopathic peptic ulcer disease (table 2) $[1,2,4$, $10,28-34]$. In a 7-year cohort, two groups of patients who presented with bleeding peptic ulcer were studied [28]. After ulcer healing, 213 patients with $H$. pylori infection underwent eradication therapy, as compared with 120 patients with idiopathic ulcer who were initially negative for H. pylori infection and were never treated with NSAID or aspirin. Rebleeding and mortality were much higher in the idiopathic peptic ulcer disease patients. Recent papers have highlighted some important clinical characteristics of $H$. pylori/NSAID-negative peptic ulcer disease, including older age, smoking, gastric hypersecretion, more concomitant disease, higher American Society of Anesthesiology score, higher complication rates and higher mortality $[28,29]$.

\section{Mucin Secretion and Proton Pump Inhibitors}

Secretion of gastric acid into the lumen is accompanied by the back-diffusion of hydrogen ions toward the mucosa, a phenomenon which is concentration-dependent [35]. The back-diffusion of hydrogen ions is counterbalanced by the release of gastric mucin. The ability of the mucus buffer layer to efficiently repel the back-diffusion of hydrogen ions depends upon the concentration of mucin which is the major structural component of gastric mucus. The higher the concentration of mucin, the greater the viscoelasticity and thickness of the mucous layer, and the greater the ability to block the back-diffusion of hydrogen ions. This thick and viscoelastic mucus layer has a higher capacity to retain bicarbonate released into the mucus layer from the mucosa.

PPIs shut down the $\mathrm{H}^{+} / \mathrm{K}^{+}$-ATPase on the apical membrane of parietal cells. PPIs thereby prevent the histamine-, gastrin- and acetylcholine-mediated acid secretion in response to stimuli (such as meals). Is this the only mechanism by which PPIs affect acid secretion? The effect of the novel PPI leminoprazole on gastric mucus secretion was studied by assaying the gastric mucin content in rats [36]. Oral administration of leminoprazole prevented the hemorrhagic lesions induced by acid-ethanol administration. Leminoprazole significantly inhibited the acid-ethanol-induced reduction of mucin in the mucus gel layer. Leminoprazole given to rats not treated with acid-ethanol accelerated the secretion of deep mucosal mucus and increased the content of soluble mucus by approximately $200 \%$ compared to controls. The effect of leminoprazole on gastric mucus secretion might contribute to healing in peptic ulcer disease, and may account for the cytoprotective properties of this drug. 
Skoczylas et al. [37] studied the effect of rabeprazole on the quantity and viscosity of gastric mucin in 21 asymptomatic volunteers in a double-blind study. The mucin content following rabeprazole administration significantly increased in both pentagastrin-stimulated (260\%) and basal conditions (141\%). The viscosity of gastric secretions during rabeprazole administration was also significantly higher both in stimulated and basal conditions. This observation has been confirmed by another study by the same group [38]. This unique pharmacological property of rabeprazole, a member of the PPI family (augmenting the production of gastric mucin, and enhancing the protective capacity of the mucous barrier), may add into its clinical efficacy in protecting the gastric and duodenal mucosa against acid and pepsin.
This may give an additional clue regarding the essential role mucin has in preventing peptic ulcer disease and in the etiology of idiopathic peptic ulcers.

\section{Conclusion}

The prevalence of idiopathic peptic ulcer disease is increasing, regardless of background $H$. pylori infection rates. A concerted effort should be made to thoroughly exclude H. pylori infection and NSAID therapy, as idiopathic peptic ulcer disease is associated with adverse outcomes. Treatment includes high-dose PPI and close surveillance. Mucin gene mutations and environmental factors affecting gastric mucin warrant further investigation.

\section{References}

$\checkmark 1$ Malfertheiner P, Chan FKL, McColl KEL: Peptic ulcer disease. Lancet 2009;374:14491461.

2 McColl KEL: How I manage H. pylori-negative, NSAID/aspirin-negative peptic ulcers. Am J Gastroenterol 2009;104:190-193.

-3 Jyotheeswaran S, Shah AN, Jin HO, Potter GD, Ona FV, Chey WY: Prevalence of Helicobacter pylori in peptic ulcer patients in greater Rochester, N.Y.: is empirical triple therapy justified? Am J Gastroenterol 1998; 93:574-578

4 Yakoob J, Jafri W, Jafri N, Islam M, Abid S, Hamid S, Alishah H, Shaikh H: Prevalence of non-Helicobacter pylori duodenal ulcer in Karachi, Pakistan. World J Gastroenterol 2005;11:3562-3565.

5 Ciociola AA, McSorley DJ, Turner K, Sykes D, Palman JB: Helicobacter pylori infection rates in duodenal ulcer patients in the United States may be lower than previously estimated. Am J Gastroenterol 1999; 94:1834-1840.

-6 Chan HL, Wu JC, Chan FK, Choi CL, Ching JY, Lec YT, Leung WK, Lau JY, Ching SC, Sung JJ: Is non-Helicobacter pylori, nonNSAID peptic ulcer a common cause of upper GI bleeding? A prospective study of 977 patients. Gastrointest Endosc 2001;53:438442.

-7 Arroyo MT, Forne M, de Argila CM, Feu F, Arenas J, de la Vega J, Ganigues V, Mora F, Castro M, Bujanda L, Cosme A, Castiella A, Gisbert JP, Hervas A: The prevalence of peptic ulcer not related to Helicobacter pylori or non-steroidal anti-inflammatory drug use is negligible in Southern Europe. Helicobacter 2004;9:249-254.
8 Nishikawa K, Sugiyama T, Kato M, Ishizuka J, Komatsu Y, Kagaya H, Katagiri M, Nishikawa S, Hakari K, Takeda H, Asaka M: NonHelicobacter pylori and non-NSAID peptic ulcer disease in the Japanese population. Eur J Gastroenterol Hepatol 2000;12:635-640.

-9 Gisbert JP, Blanco M, Mateos JM, Fernandez-Salazar L, Fernandez-Bermejo M, Cantero J, Pajares JM: H. pylori-negative duodenal ulcer prevalence and causes in $774 \mathrm{pa}-$ tients. Dig Dis Sci 1999;44:2295-2302.

10 Xia HHX, Wong BCY, Wong KW: Clinical and endoscopic characteristics of non-Helicobacter pylori, non-NSAID duodenal ulcers: a long-term prospective study. Aliment Pharmacol Ther 2001;15:1875-1882.

11 Jensen PH, Kolarich D, Packer NH: Mucintype O-glycosylation - putting the pieces together. FEBS J 2010;277:81-94.

12 Kim YS, Ho SB: Intestinal goblet cells and mucins in health and disease: recent insights and progress. Curr Gastroenterol Rep 2010; 12:319-330.

13 Hattrup CL, Gendler SJ: Structure and function of the cell surface (tethered) mucins. Annu Rev Physiol 2008;70:431-457.

14 Phillipson M, Johansson ME, Henriksnäs J, Petersson J, Gendler SJ, Sandler S, Persson AE, Hansson GC, Holm L: The gastric mucus layers: constituents and regulation of accumulation. Am J Physiol Gastrointest Liver Physiol 2008;295:G806-G812.

15 Morgenstern S, Koren R, Fraser G, Okon E, Niv Y: Gastric corpus mucin expression after partial gastrectomy, in relation to colonization with Helicobacter pylori. J Clin Gastroenterol 2001;32:218-221.
16 Morgenstern S, Koren R, Moss SF, Fraser G, Okon E, Niv Y: Does Helicobacter pylori affect gastric mucin expression? Relationship between gastric antral mucin expression and H. pylori colonization. Eur J Gastroenterol Hepatol 2001;13:19-23.

$\checkmark 17$ Ho SB, Takamura K, Anway R, Shekels LL, Toribara NW, Ota H: The adherent gastric mucous layer is composed of alternating layers of MUC5AC and MUC6 mucin proteins. Dig Dis Sci 2004;49:1598-1606.

18 Tanaka S, Mizuno M, Maga T, Yoshinoga F, Tomada J, Nasu J, Okada H, Yokota K, Oguma K, Shiratori Y, Tsuji T: H. pylori decreases gastric mucin synthesis via inhibition of galactosyltransferase. Hepatogastroenterology 2003;50:1739-1742.

19 Byrd JC, Yunker CK, Xu QS, Sternberg LR, Bresalier RS: Inhibition of gastric mucin synthesis by Helicobacter pylori. Gastroenterology 2000;118:1072-1079.

20 Kawakubo M, Ito Y, Okimura Y, Kobayashi M, Sakura K, Kasama S, Fukuda MN, Fukuda M, Katsuyama T, Nakayama Y: Natural antibiotic function of a human gastric mucin against Helicobacter pylori infection. Science 2004;305:1003-1006.

21 Celli JP, Turner BS, Afdhal NH, Keates S, Ghiran I, Kelly CP, Ewoldt RH, Mekinley GH, So P, Erramilli S, Bansil R: Helicobacter pylori moves through mucus by reducing mucin viscoelasticity. Proc Natl Acad Sci USA 2009;106:14321-14326.

22 Kobayashi M, Lee H, Nakayama J, Fukuda $\mathrm{M}$ : Roles of gastric mucin-type $\mathrm{O}$-glycans in the pathogenesis of Helicobacter pylori infection. Glycobiology 2009; 19:453-461.

-23 McGuckin MA, Lindén SK, Sutton P, Florin TH: Mucin dynamics and enteric pathogens. Nat Rev Microbiol 2011;9:265-278. 
24 Andrianifahanana M, Moniaux N, Batra SK: Regulation of mucin expression: mechanistic aspects and implications for cancer and inflammatory diseases. Biochim Biophys Acta 2006; 1765:189-222.

25 Rousseau K, Byrne C, Griesinger G, Leung A, Hill AS, Swallow DM: Allelic association and recombination hotspots in the mucin gene (MUC) complex on chromosome 11p15.5. Ann Hum Genet 2007;71:561-569.

-26 Vincent A, Perrais M, Desseyn JL, Aubert JP, Pigny P, Vanseuningen I: Epigenetic regulation (DNA methylation, histone modifications) of the11p15 mucin genes (MUC2, MUC5AC, MUC5B, MUC6) in epithelial cancer cells. Oncogene 2007;26:6566-6576.

-27 Fujisawa T, Velichko S, Thai P, Hung LY, Huang F, Wu R: Regulation of airway $M U$ C5AC expression by IL-1 $\beta$ and IL-17A; the NF- $\kappa \mathrm{B}$ paradigm. J Immunol 2009; 183: 6236-6243.

-28 Wong GL, Wong VW, Chan Y, Ching JY, Au K, Hui AJ, Lai LH, Chow DK, Siu DK, Lui YN, Wu JC, To KF, Hung LC, Chan HL, Sung JJ, Chan FK: High incidence of mortality and recurrent bleeding in patients with Helicobacter pylori-negative idiopathic bleeding ulcers. Gastroenterology 2009;137: 525-531.
29 Gisbert JP, Calvet X: Helicobacter pylori-negative duodenal ulcer disease. Aliment Pharmacol Ther 2009;30:791-815.

30 Bank S, Blumstein M, Greenberg RE, Magier D, Lavin PT: Efficacy of famotidine in the healing of active benign gastric ulceration: comparison of nonsteroidal anti-inflammatory- or aspirin-induced gastric ulcer and idiopathic gastric ulceration. Long Island Jewish Medical Center Acid-Peptic Study Group. Clin Ther 1993;15:36-45.

31 Xia HH, Phung N, Kalantar JS, Talley NJ: Demographic and endoscopic characteristics of patients with Helicobacter pylori positive and negative peptic ulcer disease. Med J Aust 2000;173:515-519.

32 Arents NL, Thijs JC, van Zwet AA, Kleibeuker JH: Does the declining prevalence of $\mathrm{He}$ licobacter pylori unmask patients with idiopathic peptic ulcer disease? Trends over an 8 -year period. Eur J Gastroenterol Hepatol 2004;16:779-783.

33 Chen TS, Chang FY: Clinical characteristics of Helicobacter pylori-negative duodenal ulcer disease. Hepatogastroenterology 2008; 55:1615-1618.
34 Boltin D, Helpern M, Levi Z, Vilkin A, Morgenstern S, Ho SB, Niv Y: Gastric mucin expression in Helicobacter pylori, nonsteroidal anti-inflammatory drug and idiopathic ulcers. World J Gastroenterol 2012 (in press).

35 Sarosiek J, Mizuta K, Slomiany A, Slomiany BL: Effect of acetylsalicylic acid on gastric mucin viscosity, permeability to hydrogen ion and susceptibility to pepsin. Biochem Pharmacol 1986;35:4291-4295.

- 36 Ishihara K, Ichikawa T, Komuro Y, Ohara S, Hotta K: Effect on gastric mucus of the proton pump inhibitor leminoprazole and its cytoprotective action against ethanol-induced gastric injury in rats. Arzneimittelforschung 1994;44:827-830.

- 37 Skoczylas T, Sarosiek I, Sostarich S, McElhinney C, Durham S, Sarosiek J: Significant enhancement of gastric mucin content after rabeprazole administration: its potential clinical significance in acid-related disorders. Dig Dis Sci 2003;48:322-328.

38 Jaworski T, Sarosiek I, Sostarich S, Soesen K, Connor M, Brotze S, Wallner G, Sarosiek J: Restorative impact of rabeprazole on gastric mucus and mucin production impairment during naproxen administration: its potential clinical significance. Dig Dis Sci 2005;50: 357-365. 